\title{
Entrepreneurial Finance and Economic Growth
}

\author{
Paolo E. Giordani* \\ June 2013
}

\begin{abstract}
This paper incorporates the process of entrepreneurial finance into an endogenous growth model with horizontal innovation (Romer, 1990; Jones, 1995b). To capture the market frictions existing in the financing of innovation, entrepreneurial finance is described as a process of "search and matching" between entrepreneurs proposing their innovative ventures and capitalists selecting and financing the most valuable projects. We determine the amount of resources devoted to innovation along the balanced growth path. The welfare analysis highlights the sub-optimality of the equilibrium innovative efforts due to search and bargaining frictions. We analyze the role of the policy maker to restore the optimality of investments in innovation.
\end{abstract}

Keywords: Financing of innovation, search and matching process, endogenous growth.

JEL Classification: 031, 041, L26.

${ }^{*}$ LUISS "Guido Carli" University, Department of Economics and Finance, Viale Romania 32, 00197 Roma, Italy. Tel.: +39 0685225912. E-mail: pgiordani@luiss.it. 


\section{Introduction}

The process of innovation in capitalistic economies is fraught with several market frictions and failures. The most commonly known source of failure is the so-called problem of "appropriability", first clearly stated by Arrow (1962). Since a new idea has a non-rivalrous nature, some form of intellectual property rights may be necessary to provide inventors with the right incentives to spend time and resources in the discovery process. A second, and probably less extensively investigated, source of market failure is concerned with the process of financing innovation, that is, with the problem for the innovator of gathering enough funds to finance her entrepreneurial venture. This paper focuses on this second issue.

Both microeconomic theory and empirical evidence have long recognized the potential obstacles hidden in the process of financing innovation, suggesting that inventors may be financially constrained. ${ }^{1}$ Theoretical arguments, proposed to explain financial market imperfections in the innovation sector, range from transaction costs and tax advantages to agency costs due to informational asymmetries between the innovator (agent) and the financier (principal). While these aspects are common to any financing relationship, a number of additional elements suggest that frictions can be even more severe for innovative investments. First, innovations are "unique" events, and the process aimed at producing them is an uncertain and largely unpredictable economic activity (Cozzi and Giordani, 2011). Secondly, as most of the R\&D expenditure is on intangible assets (such as scientists' wages), this expenditure provides bad collateral for the financier (Almeida and Campello, 2004). Finally, a quality-signaling strategy, which could be used to attenuate the problem of asymmetric information between the entrepreneur and the financier, is hardly implementable in the market of innovation: inventors may be reluctant to signal the quality of their own project, as they may reasonably fear that competitors steal their new idea (Bhattacharya and Ritter, 1983).

On the other hand, macroeconomic literature, and in particular endogenous innovationdriven growth theory, usually abstract from the problem of financing innovation (see for instance, Romer (1990), Aghion and Howitt (1992), Grossman and Helpman (1991a,b) and subsequent developments). In such models, a frictionless financial market exists that channels resources from savers to the $R \& D$ process, revealing the true value of each innovation. The process of innovation is depicted as a routinized and essentially predictable process.

\footnotetext{
${ }^{1}$ For a thorough review of these issues, refer to Hall and Lerner (2010).
} 
This paper casts a bridge between these two streams of literature. It develops an endogenous growth model where the financing process of innovation is characterized by market frictions, and it analyzes the welfare implications of these frictions. In particular, we construct a scale-free endogenous growth model with horizontal innovation (Romer, 1990, Grossman and Helpman, 1991b, Jones, 1995a,b). The economy is characterized by three sectors: (i) a final good sector, in which a final good is produced competitively employing labor and an array of intermediate goods; (ii) an intermediate good sector, in which each intermediate good is produced and sold by a monopolistic firm, and (iii) an "industry of new ideas", which employs labor to introduce new varieties of intermediate goods. Technological progress is embodied by the increase in the number of intermediate good varieties introduced into the market.

The peculiarity of our growth model lies in the way technological progress occurs: a new intermediate variety is the outcome of a successful process of search and matching between entrepreneurs (or innovators), who come up with new ideas and capitalists (or financiers), who select what they believe are the most promising ideas and help launch them in the market. In particular, entrepreneurs and financiers meet pairwise and, once a successful matching has occurred, they bargain over the distribution of the monopoly rents associated with the "discovery" of the new intermediate good variety.

The model studies the occupational choice of economic agents. Agents have to decide whether to work in the final good sector or in the "industry of ideas". In this last case, they can choose to devote their time to come up with a new idea, and hence to become entrepreneurs. Alternatively, they may opt for screening and selecting the most valuable ideas deserving financial funds, in which case they become capitalists. We find the employment allocation across the three occupational possibilities of this economy along the balanced growth path: manufacturing, entrepreneurial and capitalistic activities. This allocation is found by imposing that, at equilibrium, the expected returns from each of these activities be identical.

We show that the financial market for innovation is characterized by a complementary relationship between entrepreneurs and financiers, in that the number of entrepreneurs is increasing in the number of financiers, and viceversa. The intuition for this result is straightforward: a higher number of financiers simply raises the entrepreneur's chance of having her own project being selected and financed, and thus it raises the incentive to become entrepreneur, and viceversa. Because of this thick market externality, we cannot exclude the possibility that the economy admits multiple stationary equilibria. 
The equilibrium employment allocation is then compared to the optimal allocation obtained through the welfare analysis. The amount of total labor resources that the market allocates to entrepreneurial innovation is sub-optimal and, moreover, it is inefficiently distributed between entrepreneurs and capitalists. In particular, in addition to the usual externalities associated with the class of horizontal innovation models $\grave{a}$ la Romer (1990), our model allows us to evaluate the welfare effects of the search frictions in the market for innovation. As we will clarifly in Section 5, the occupational choice of each economic agent affects the payoff and the choice of all other agents. In particular, the entry of an entrepreneur stimulates the entry of capitalists ("easy matching effect") and discourages the entry of additional entrepreneurs ("stepping on toes effect"), and a symmetric reasoning applies to the entry of a capitalist. Moroever, the fact that the allocation of the monopoly rents is made according to a Nash bargaining process between entrepreneurs and financiers introduces an additional source of frictions: the bargaining power of each agent does not necessarily reflect their marginal productivity in the innovation process. The overall effect on the market of innovation, which is not internalized by either entrepreneurs or capitalists when making their choices, may be positive or negative. As a result, total market-driven innovative efforts may be higher or lower than optimal. The existence of these external effects is an additional reason for the policy maker to intervene in the innovation sector.

The modeling strategy that we follow in this paper is meant to capture some salient features of the financial market for innovation. In the words of Phelps (2009, p. 50), "the classical supply-and-demand apparatus does not apply to the core market of capitalist economies - the capital market, particularly the market for capital going to entrepreneurs' innovative projects". It takes time and resources for an entrepreneur to find and convince a financier about the profitability of her business venture. At the same time, it takes time and resources for a financier to find the innovative project that she believes it is worth financing. The financial market for innovation is then, probably, better represented as a decentralized market where heterogeneous entrepreneurs and financiers meet bilaterally according to a matching technology. Again in the words of Phelps (2009, p. 52), "the capital market is a sort of matching process that matches a financier to an entrepreneur who the former sees as having a model compatible with his own model". The search and matching process is a modeling tool that allows us to represent succintly all frictions characterizing the process of financing innovation - such as information imperfections, or the entrepreneurs' and capitalists' heterogeneities in 
skills, location, beliefs etc. ${ }^{2}$

This representation of the financing relationship is also especially apt to describe the practical functioning of the modern venture capital (VC) industry, where a financed entreprenerial project is the result of a meeting between an entrepreneur submitting her business plan, and a VC fund that is expected to bring managerial and/or technical expertise together with financial investments (see for instance Gompers and Lerner, 1999). Venture capital is a relatively novel model of innovation financing, and it complements the more traditional, corporate R\&D model. A debate is open as to whether entrepreneurial finance is going to replace corporate $R \& D$ as the new standard of financing innovation. On the one hand, the former still represents a tiny fraction of the latter (Lerner, 2010). On the other hand, evidence suggests that entrepreneurial investments are growing faster and are more productive than R\&D investments. ${ }^{3}$ Moreover, they are disproportianately concentrated in the most innovative industries (ICT, biotechnology and, more recently, energy and environment). Our model can be interpreted as a first attempt to introduce, into an endogenous growth model, a role for the venture capital sector as the engine of economic growth.

The rest of the paper is organized as follows. Section 2 further discusses the related literature. Section 3 describes the model, while Section 4 characterizes the balanced growth path(s) of the economy and carries out the comparative statics analysis. Section 5 carries out the welfare analysis and discusses the policy implications. Section 6 concludes with a few remarks.

\section{Related Literature}

This paper is broadly related to the vast literature on the link between finance, innovation and economic growth. Key contributions in this field include King and Levine (1993), Aghion et al. (2004), Greenwood et al. (2010), Chiu et al. (2013) (for a survey see Levine, 2005). In this respect, our specific contribution is the one of incorporating the process of entrepreneurial finance into an otherwise standard endogenous growth model.

Other papers have described entrepreneurial finance as a search and matching

\footnotetext{
${ }^{2}$ Prior to finance, search theory has been extensively used in diverse economics fields, such as labor economics, monetary theory, and the theory of marriage.

${ }^{3}$ According to an empirical study by Kortum and Lerner (2000), one dollar of venture capital generates as much innovation as three dollars of traditional corporate R\&D.
} 
process beween entrepreneurs and capitalists. A few papers emphasize the microeconomic foundations of the search and bargaining frictions (Silveira and Wright, 2007, Silveira and Wright, 2010). Others focus on the nature and on the implications of the relationship between entrepreneurs and capitalists (Cipollone and Giordani, 2013), or on the contractual content of this relationship (Inderst and Muller, 2004, Boadway et al., 2005). This paper brings this formalization into a general equilibrium framework, and it analyzes its welfare consequences. The great step ahead of R\&D-based growth models with respect to neoclassical growth, that is, the idea that "inventions require inventors" (Jones, 1995b, p.760), is here further extended to the idea that inventions require not only inventors but also capitalists. In this respect, two contributions close to ours are the one by Michelacci and Suarez (2004), and the one by Bauer and Rodriguez Mora (2012). The former introduce the process of entrepreneurial finance into an endogenous growth model, although their focus is on the role of a well developed stock market in fostering innovation and growth. The latter investigate the effects of (endogenous) search and bargaining frictions on the dynamics of a growing economy (both a Solow-like economy and an AK-type economy). They neglect welfare considerations, that represent a major focus of our analysis.

\section{The Model}

The economy is composed of three sectors: (i) a final good sector, in which the final good is produced competitively employing labor and an array of intermediate goods; (ii) an intermediate good sector, in which each intermediate good is produced and sold by a monopolistic firm, and (iii) the industry of ideas, which employs entrepreneurs and capitalists to introduce new varieties of intermediate goods. These ideas, that result from a successful matching between them, are immediately patented and sold to intermediate good firms that monopolize the market for that particular variety. Let us start from the characterization of the sector where innovation takes place.

\subsection{The Industry of Ideas}

Total population in this economy is denoted by $L$ and is assumed to be growing exponentially at constant rate $n$ (we omit time subscripts for notational simplicity). Economic agents have to decide whether to work in the industry of ideas or in the final good sector. In the first case, they can act as entrepreneurs or as capitalists. 
Denoting by $L_{E}, L_{F}, L_{Y}$ respectively the number of entepreneurs, capitalists and final good workers, the labor market clearing condition writes as

$$
L_{E}+L_{F}+L_{Y}=L
$$

An agent devoting her unit of time to innovation comes up with a new idea. However, in order for this raw entrepreneurial idea to become a marketable innovation, the idea needs the support of a capitalist evaluating its potential profitability. An innovation is the result of a process of successful search and matching between an entrepreneur and a capitalist. The innovation function - representing the production function of knowledge - is a constant-return-to-scale (CRS) Cobb-Douglas technology:

$$
\dot{A}=\beta \cdot\left(L_{E}\right)^{a}\left(L_{F}\right)^{1-a},
$$

where $A$ is the (increasing) measure of ideas (incorporated into intermediate input varieties), and $\beta \in R_{+}$is a productivity parameter that captures the efficiency of the matching process.

Note that, when $a=1$, the model collapses to a standard semi-endogenous growth model (see for instance Jones, 1995b). Notice also that our results hold for any CRS function. Cipollone and Giordani (2013), however, give an empirical estimate of the innovation process taking place in the Business Angel market of the most developed countries. They show that a CRS Cobb-Douglas technology is among the functional specifications that better capture the matching process between the business angels and the entrepreneurs submitting their projects to them. This functional form is also useful for tractability. ${ }^{4}$

Given the "matching function" in (1), the arrival rate of ideas (or the instantaneous probability of matching) for entrepreneurs is

$$
\alpha_{E}=\frac{\dot{A}}{L_{E}}=\beta \cdot\left(\frac{L_{F}}{L_{E}}\right)^{1-a},
$$

\footnotetext{
${ }^{4}$ Two more technical remarks on (1) are in order. First, the hypothesis of zero knowledge spillovers - that is, the idea that the stock of knowledge $A$ does not directly affect the rate of innovation - is only made for simplicity. Secondly, while at first glance it may seem odd to admit the necessity of capitalists for innovation and then not to consider capital as an input in the production function of new knowledge, this assumption is only introduced to simplify the analysis and is without loss of generality. We could have assumed a function such as$$
\dot{A}=\beta\left(L_{E}\right)^{a} \cdot\left(L_{F}\right)^{b} \cdot(K)^{1-a-b}
$$

Capital would be provided by an otherwise perfect financial market thanks to the "intercession" of capitalists.
} 
while the one for capitalists is

$$
\alpha_{F}=\frac{\dot{A}}{L_{F}}=\beta \cdot\left(\frac{L_{E}}{L_{F}}\right)^{a} .
$$

Let us now analyze the occupational choice of the agents in this economy. If they work in the final good sector (to be characterized in the next subsection), they gain a wage rate, denoted by $w$. If they choose to become entrepreneurs, they gain the chance of a successful matching with a capitalist, denoted by $v_{E}^{0}$. Finally, if they choose to become capitalists, they gain the chance of a successful matching with an entrepreneur, denoted by $v_{F}^{0}$ (as we will see, in equilibrium it must be $v_{E}^{0}=w=v_{F}^{0}$ ). We now use dynamic programming to determine the values of the various states.

The expected payoff associated with becoming an entrepreneur is defined by the following asset equation:

$$
r v_{E}^{0}=\alpha_{E}\left(v_{E}^{1}-v_{E}^{0}\right)+\dot{v}_{E}^{0}
$$

where $r$ is the rental rate of capital, and $v_{E}^{1}$ represents the value of a successful matching for an entrepreneur. This value is defined by

$$
r v_{E}^{1}=\bar{\theta} \pi+v_{E}^{0}-v_{E}^{1}+\dot{v}_{E}^{1}
$$

where $\bar{\theta} \pi$ is the fraction of the monopoly profits accruing to the entrepreneur prevailing in the market. These asset equations have the usual interpretations. Equation (2) says that the per period value of choosing to be an entrepreneur must be equal to the probability of a successful matching with a capitalist times the payoff associated with this chance, plus the capital gain or loss that may occur over time. An analogous interpretation can be provided for equation (3). Solving the system in $v_{E}^{0}$ and $v_{E}^{1}$, we obtain

$$
v_{E}^{0}=\frac{\bar{\theta} \pi \alpha_{E}}{\left(r-\frac{\dot{v}_{E}^{0}}{v_{E}^{0}}\right)+\alpha_{E}\left(r-\frac{\dot{v}_{E}^{1}}{v_{E}^{1}}\right)+\left(r-\frac{\dot{v}_{E}^{1}}{v_{E}^{1}}\right)\left(r-\frac{\dot{v}_{E}^{0}}{v_{E}^{0}}\right)} .
$$

The value of $v_{E}^{1}$ can then be obtained substituting for the expression of $v_{E}^{0}$ given above into the following:

$$
v_{E}^{1}=\frac{\bar{\theta} \pi+v_{E}^{0}}{1+r-\frac{\dot{v}_{E}^{1}}{v_{E}^{1}}}
$$

The expected payoff associated to becoming a capitalist is instead defined by

$$
r v_{F}^{0}=\alpha_{F}\left(v_{F}^{1}-v_{F}^{0}\right)+\dot{v}_{F}^{0},
$$


where $v_{F}^{1}$ represents the value of a successful matching for a capitalist, which is given $\mathrm{by}^{5}$

$$
r v_{F}^{1}=(1-\bar{\theta}) \pi+v_{F}^{0}-v_{F}^{1}+\dot{v}_{F}^{1}
$$

where $(1-\bar{\theta}) \pi$ is the fraction of the monopoly profits accruing to the capitalists prevailing in the market. Solving the system in $v_{F}^{0}$ and $v_{F}^{1}$ we obtain

$$
v_{F}^{0}=\frac{(1-\bar{\theta}) \pi \alpha_{F}}{\left(r-\frac{\dot{v}_{F}^{0}}{v_{F}^{0}}\right)+\alpha_{F}\left(r-\frac{\dot{v}_{F}^{1}}{v_{F}^{1}}\right)+\left(r-\frac{\dot{v}_{F}^{1}}{v_{F}^{1}}\right)\left(r-\frac{\dot{v}_{F}^{0}}{v_{F}^{0}}\right)} .
$$

The value of $v_{F}^{1}$ can be found by substituting for the expression above into

$$
v_{F}^{1}=\frac{(1-\bar{\theta}) \pi+v_{F}^{0}}{1+r-\frac{\dot{v}_{F}^{1}}{v_{F}^{1}}}
$$

\subsection{The Final Good Sector}

Final good $Y$ is produced competitively according to to the following Cobb-Douglas technology: ${ }^{6}$

$$
Y=L_{Y}^{1-\gamma} \int_{0}^{A} x_{j}^{\gamma} d j
$$

where $L_{Y}$ denotes total labor employed in the final good sector, $x_{j}$ is the $j^{\text {th }}$ intermediate input, and $A$ is the measure of varieties of these inputs. Competitive firms solve the following maximization problem:

$$
\max _{L_{Y}, x_{j}}\left[L_{Y}^{1-\gamma} \int_{0}^{A} x_{j}^{\gamma} d j-w L_{Y}-\int_{0}^{A} p_{j} x_{j} d j\right]
$$

where $p_{j}$ is the price of the $j^{\text {th }}$ intermediate good, and where the final good is assumed as numeraire. From first-order conditions, we obtain $p_{j}=\gamma\left(x_{j} / L_{Y}\right)^{\gamma-1}$ and

$$
w=(1-\gamma) \frac{Y}{L_{Y}}
$$

\footnotetext{
${ }^{5}$ Assume for simplicity that each capitalist can enter into one and only one project at a time, and that each entrepreneur needs one and only one capitalist.

${ }^{6}$ The rest of the model follows a standard scale-free endogenous growth model with horizontal innovation. The closest framework is Jones (1995b).
} 


\subsection{The Intermediate Good Sector}

The intermediate good sector is composed of an infinite number of firms distributed along the measure $[0, A]$. After having purchased the (infinitely-lived) patent for a variety of intermediate good from the market of ideas, each of these firms monopolizes the market for that particular variety. One unit of raw capital, rented at rate $r$, produces one unit of any intermediate input. No depreciation takes place. The $j^{\text {th }}$ intermediate good producer solves the following standard monopoly problem:

$$
\max _{x_{j}}\left[p_{j}\left(x_{j}\right) x_{j}-r x_{j}\right] .
$$

Substituting for $p_{j}$ given from above and maximizing we obtain

$$
x_{j}=\left(\frac{r}{\gamma^{2}}\right)^{\frac{1}{\gamma-1}} L_{Y} \equiv x \text { and } p_{j}=\frac{r}{\gamma} \equiv p \quad \forall j .
$$

We can also give an expression for the monopoly profits as

$$
\pi_{j}=\gamma(1-\gamma) \frac{Y}{A} \equiv \pi \quad \forall j .
$$

Note that the symmetric structure of the economy makes quantities, prices and profits independent of the specific variety produced. Thus it is

$$
K=\int_{0}^{A} x_{j} d j=\int_{0}^{A} x d j=A x .
$$

As a result, the aggregate production function can be written in the more familiar expression

$$
Y=(K)^{\gamma}\left(A L_{Y}\right)^{1-\gamma} .
$$

Given that the functional distribution of income implies

$$
w L_{Y}+r K+\pi A=Y
$$

substituting for $w$ and $\pi$ given above, we obtain

$$
r=\gamma^{2} \frac{Y}{K}
$$

implying that capital receives a smaller share of the average product of capital compared to the perfect competition case. 


\subsection{Consumption Decisions}

Finally, consider the consumption decision of the representative household. Following the standard formalization, the problem is the one of maximizing an additively separable utility function, such as

$$
U=\int_{0}^{\infty} \exp [-\rho t] \frac{c(t)^{1-\phi}-1}{1-\phi} d t
$$

(where $c$ represents consumption per capita, $C / L$ ) under the usual dynamic budget constraint $(\dot{K}=Y-C)$. The time path of consumption per capita must obey the following Euler equation

$$
\frac{\dot{c}}{c}=\frac{1}{\phi}(r(t)-\rho-n)
$$

\section{The Balanced Growth Path}

From now onwards we focus on the steady state. From the labor market clearing condition it must be that, along the balanced growth path, $g_{L_{F}}=g_{L_{E}}=g_{L_{Y}}=n$. Dividing the production function for ideas by $A$

$$
g_{A}=\frac{\beta \cdot\left(L_{E}\right)^{a}\left(L_{F}\right)^{1-a}}{A},
$$

and taking logs and derivatives, we obtain that

$$
g_{A}=n,
$$

that is to say, the rate of technological progress in this economy is equal to the growth rate of population. Given the expression of the aggregate production function (6), the growth rate of income per capita, $y=Y / L$, must also be equal to $n$ (as usual in the class of "semi-endogenous" innovation-driven growth models).

From (7), and knowing that $\dot{c} / c=\dot{y} / y=n$, we can determine the (constant) value of $r$ along the steady state, which is

$$
r=n(\phi+1)+\rho .
$$

Working on (2), we derive that in steady state $\dot{v}_{E}^{0} / v_{E}^{0}=\dot{v}_{E}^{1} / v_{E}^{1} \cdot{ }^{7}$ Moreover, dividing (3) by $v_{E}^{1}$ and rearranging, we get

$$
1+r-\frac{v_{E}^{0}}{v_{E}^{1}}-\frac{\dot{v}_{E}^{1}}{v_{E}^{1}}=\frac{\bar{\theta} \pi}{v_{E}^{1}} .
$$

\footnotetext{
${ }^{7}$ We obtain this by dividing both sides of (2) by $v_{E}^{0}$ and using the fact that $\alpha_{E}$ must be constant along the steady state.
} 
Knowing that all terms on the left-hand side are constant along the steady state, then it must be $\dot{v}_{E}^{1} / v_{E}^{1}=\dot{\pi} / \pi$. Since from (5) we know that the latter is equal to $n$, it must be $\dot{v}_{E}^{0} / v_{E}^{0}=\dot{v}_{E}^{1} / v_{E}^{1}=n$.

Along the steady state, and exploiting condition (8), values $v_{E}^{0}$ and $v_{E}^{1}$ can then finally be expressed as

$$
v_{E}^{0}=\frac{\bar{\theta} \pi \alpha_{E}}{(n \phi+\rho)\left(1+\alpha_{E}\right)+(n \phi+\rho)^{2}} \text { and } v_{E}^{1}=\frac{\bar{\theta} \pi+v_{E}^{0}}{1+n \phi+\rho} .
$$

Repeating exactly the same steps for $v_{F}^{0}$ and $v_{F}^{1}$, we obtain

$$
v_{F}^{0}=\frac{(1-\bar{\theta}) \pi \alpha_{F}}{(n \phi+\rho)\left(1+\alpha_{F}\right)+(n \phi+\rho)^{2}} \text { and } v_{F}^{1}=\frac{(1-\bar{\theta}) \pi+v_{F}^{0}}{1+n \phi+\rho} .
$$

Defining employment across the three activities in share values, that is, defining variables $l_{i} \equiv L_{i} / L$ for $i=Y, E, F$, we can characterize the steady state equilibrium as the triple $\left(l_{Y}, l_{E}, l_{F}\right)$ that solves the following system

$$
\left\{\begin{array}{l}
v_{E}^{0}=w \\
v_{F}^{0}=w \\
l_{E}+l_{F}+l_{Y}=1
\end{array}\right.
$$

where the expressions for $v_{E}^{0}, v_{F}^{0}$ and $w$ are respectively given in (9), (10) and (4).

The first two equations of (11) state that, at equilibrium, the returns from being employed in the manufacturing sector must be equal to the expected returns from entrepreneurial as well as from capitalistic activities. Notice that, while $w$ is a certain income, both $v_{E}^{0}$ and $v_{F}^{0}$ are uncertain. They must be equal at equilibrium even for risk-averse agents however, because - as usual in the class of innovation-driven growth models (Grossman and Helpman, 1991b) - investors are able to completely diversify their portfolio along the interval of intermediate good sectors $[0, A]$ through the intermediation of costless financial institutions and, hence, they are able to hedge completely against the volatility of the innovation returns.

While the third equation of (11) represents the labor market-clearing condition, the first two equations can be interpreted as the implicit best response functions of, respectively, entrepreneurs to capitalists and of capitalists to entrepreneurs. It is easy to prove that both functions are positively-sloped $\left(d l_{i} / d l_{-i}>0\right.$ for $\left.i=E, F\right)$, thus signaling a strategic complementarity between the two main actors of the innovation process. The intuition for this complementarity goes as follows. In the first equation, 
capturing the effect of capitalists on entrepreneurs, an increase in $l_{F}$ raises the probability of matching $\alpha_{E}$ for an entrepreneur, and thus it raises the expected returns from becoming entrepreneur, $v_{E}^{0}$. This induces a rise in the number of entrepreneurs. A totally symmetric reasoning applies to the second equation. ${ }^{8}$

Using (9), (10), (4) and (5), and using the fact that $\dot{A} / A=n, \alpha_{E}=\dot{A} / L_{E}$, $\alpha_{F}=\dot{A} / L_{F}$, we can rewrite system (11) as

$$
\left\{\begin{array}{l}
\frac{n \bar{\theta} \gamma \frac{l_{Y}}{l_{E}}}{(n \phi+\rho)\left(1+\alpha_{E}\right)+(n \phi+\rho)^{2}}=1 \\
\frac{n(1-\bar{\theta}) \gamma_{Y}}{l_{F}} \\
\frac{n \phi+\rho)\left(1+\alpha_{F}\right)+(n \phi+\rho)^{2}}{(n \phi}=1 \\
l_{E}+l_{F}+l_{Y}=1
\end{array}\right.
$$

where $\alpha_{E}=\beta \cdot\left(l_{F} / l_{E}\right)^{1-a}$ and $\alpha_{F}=\beta \cdot\left(l_{E} / l_{F}\right)^{a}$. While system (12) cannot be solved explicitly in the three unknowns $l_{E}, l_{F}, l_{Y}$, the strategic complementarity between entrepreneurs and financiers indicates the theoretical possibility of multiple equilibria.

As usual in the class of innovation-driven growth models, the monopolistic rent $\pi$ associated with the new variety of intermediate good is totally extracted by the operators of the innovation sector. In a perfectly competitive market for entrepreneurial and capitalistic skills, the operators' contributions to the innovation process would be paid proportionally to their marginal productivities. From (1), the marginal productivities for entrepreneurs and capitalists can be written respectively as $a \beta\left(l_{F} / l_{E}\right)^{1-a}$ and $(1-a) \beta\left(l_{E} / l_{F}\right)^{a}$. This allocative rule then implies that the profit share ratio $(\bar{\theta} \pi /(1-\bar{\theta}) \pi)$ be equal to the marginal productivity ratio $\left(a \beta\left(l_{F} / l_{E}\right)^{1-a} /(1-a) \beta\left(l_{E} / l_{F}\right)^{a}\right)$, that is, and simplifying where possible:

$$
\frac{\bar{\theta}^{c}}{\left(1-\bar{\theta}^{c}\right)}=\frac{a}{1-a} \cdot \frac{l_{F}}{l_{E}} .
$$

where superscript $c$ refers to competition in the market for entrepreneurial and capitalistic skills. Expression (13) tells us that the profit shares accruing to entrepreneurs and financiers are governed by two forces: the relative elasticities of innovation to the inputs $(a /(1-a))$ and their relative number $\left(l_{F} / l_{E}\right)$. Solving $(13)$ for $\bar{\theta}^{c}$, we obtain

$$
\bar{\theta}^{c}=\frac{\frac{a}{1-a} \frac{l_{F}}{l_{E}}}{1+\frac{a}{1-a} \frac{l_{F}}{l_{E}}} .
$$

\footnotetext{
${ }^{8}$ Cipollone and Giordani (2013) provide empirical evidence that support the existence of such complementarity in the business angel market. They also study the theoretical implications of this complementarity for the dynamics of the innovation process in a partial equilibrium framework.
} 
As expected, the entrepreneurs' profit share responds positively to $a$ and $l_{F}$ and negatively to $l_{E}$ (and, of course, viceversa for capitalists). ${ }^{9}$ Although we cannot find the explicit values for the three unknowns $l_{E}^{c}, l_{F}^{c}, l_{Y}^{c}$ (even after substituting for $\bar{\theta}^{c}$ found above inside system (12)), we can however prove their sub-optimality (see Section 5).

\subsection{The Steady-State under Nash Bargaining of Monopoly Rents}

In the classical economic literature on search and matching (as of Diamond, 1982, Mortensen, 1982, and Pissarides, 1984), the general idea of a decentralized market is captured via a model where "potential traders are brought together pairwise by a given stochastic matching technology and, once together, their terms of trade are determined instantaneously as the outcome of a bargaining process that uses a given surplus-sharing rule" (Hosios, 1990, p. 279). In the next subsection, and in line with the rest of the literature on entrepreneurial finance cited in Section 2, we follow this tradition and combine search and matching with a bargaining process between the two actors of the innovation process over the distribution of monopoly rents. We do it because this is how both leading scholars in the field (Gompers and Lerner, 1999), as well practitioneers in the venture capital market, say this market works in practice: an equity contract between the entrepreneur and the financier, where their respective share of future profits reflects their current bargaining power. ${ }^{10}$

Now suppose that, when a successful matching occurs, the entrepreneur and the capitalist bargain over the profits generated by that match, $\pi$. In particular, suppose that the shares of these profits are determined as a solution to a generalized Nash bargaining problem. When an entrepreneur and a capitalist meet, they negotiate over

\footnotetext{
${ }^{9}$ Note that the strategic complementarity between entrepreneurs and capitalists highlighted above is here reinforced by the additional effect passing through the (now endogenous) profit share, $\bar{\theta}^{c}$ : given that $d \bar{\theta}^{c} / d l_{F}>0$, an increase in $l_{F}$ raises the entrepreneurs' profit share $\left(\bar{\theta}^{c}\right)$ and thus further raises the returns from becoming an entrepreneur. A totally symmetric reasoning applies to the effect of entrepreneurs on capitalists.

${ }^{10}$ Moreover, this bargaining power is not immutable over time but responds to the ups and downs of the market. For instance, Inderst and Muller (2004) provide anecdotal evidence on the 2001 internet bubble: during the peak, as "too much money was chasing too few deals" (Gompers and Lerner, 2000), entrepreneurs were able to obtain very good contractual conditions. The successive burst of the bubble, however, brought about "changes in deal terms... all of which [were] designed to enhance returns and the quantum of control enjoyed by nervous investors" (Bartlett, 2001, as cited by Inderst and Muller, 2004, p. 321).
} 
their respective share of monopoly profits $(\theta, 1-\theta)$ taking as given the shares prevailing in the market $(\bar{\theta}, 1-\bar{\theta})$. Reminding the expressions for $v_{E}^{1}$ and $v_{F}^{1}$ written in (9) and (10), we can define the surpluses as

$$
\begin{aligned}
& S_{E}=v_{E}^{1}-v_{E}^{0}=\frac{\theta \pi+v_{E}^{0}}{1+n \phi+\rho}-v_{E}^{0}=\frac{\theta \pi-v_{E}^{0}(n \phi+\rho)}{1+n \phi+\rho} \\
& S_{F}=v_{F}^{1}-v_{F}^{0}=\frac{(1-\theta) \pi+v_{F}^{0}}{1+n \phi+\rho}-v_{F}^{0}=\frac{(1-\theta) \pi-v_{F}^{0}(n \phi+\rho)}{1+n \phi+\rho}
\end{aligned}
$$

where $v_{E}^{0}, v_{F}^{0}$ are interpreted as the threat points for, respectively, the entrepreneur and the capitalist.

The Nash bargaining problem is the one of maximizing the following expression with respect to $\theta$ :

$$
\left(S_{E}\right)^{\sigma} \cdot\left(S_{F}\right)^{1-\sigma}
$$

where $\sigma$ stands for the bargaining power of the entrepreneur. Taking the first order condition and simplifying, we obtain

$$
\sigma S_{F}-(1-\sigma) S_{E}=0
$$

Plugging the values for $S_{E}, S_{F}$ written in (14) into the above expression and rearranging we obtain

$$
\theta \pi=\sigma \pi+(1-\sigma) v_{E}^{0}(n \phi+\rho)-\sigma v_{F}^{0}(n \phi+\rho)
$$

Knowing that

$$
v_{E}^{0}=\frac{\bar{\theta} \pi \alpha_{E}}{(n \phi+\rho)\left(1+\alpha_{E}\right)+(n \phi+\rho)^{2}}, v_{F}^{0}=\frac{(1-\bar{\theta}) \pi \alpha_{F}}{(n \phi+\rho)\left(1+\alpha_{F}\right)+(n \phi+\rho)^{2}},
$$

where $\bar{\theta}$ is the profit share of the entrepreneur prevalent in the market, and plugging these values into (15), we obtain

$$
\theta \pi=\sigma \pi+\frac{(1-\sigma) \bar{\theta} \pi \alpha_{E}}{1+\alpha_{E}+n \phi+\rho}-\frac{\sigma(1-\bar{\theta}) \pi \alpha_{F}}{1+\alpha_{F}+n \phi+\rho}
$$

Finally, knowing that in equilibrium it must be $\theta=\bar{\theta}$, we can solve for $\bar{\theta}$ to obtain

$$
\bar{\theta}^{b}=\frac{\sigma\left[\alpha_{E}+1+n \phi+\rho\right]}{1+n \phi+\rho+\sigma \alpha_{E}+(1-\sigma) \alpha_{F}}
$$

where superscript $b$ stands for bargaining. 
Plugging the expression for $\bar{\theta}^{b}$ given above into system (12) and simplifying where possible, we finally obtain ${ }^{11,12}$

$$
\left\{\begin{array}{l}
\frac{n \gamma l_{Y}}{(n \phi+\rho)\left(1+n \phi+\rho+\sigma \alpha_{E}+(1-\sigma) \alpha_{F}\right)}=\frac{l_{E}}{\sigma} \\
\frac{n \gamma l_{Y}}{(n \phi+\rho)\left(1+n \phi+\rho+\sigma \alpha_{E}+(1-\sigma) \alpha_{F}\right)}=\frac{l_{F}}{1-\sigma} \\
l_{E}+l_{F}+l_{Y}=1
\end{array}\right.
$$

It is immediate to show that $l_{E}^{b} / l_{F}^{b}=\sigma /(1-\sigma)$. This implies that the relative importance of entrepreneurs over capitalists reflects their respective bargaining power. In particular, it is $l_{E}^{b}>l_{F}^{b}$ if and only if $\sigma>1 / 2$, that is, if and only if the bargaining power of entrepreneurs is higher than the one of capitalists. Given that that $l_{E}^{b} / l_{F}^{b}=$ $\sigma /(1-\sigma)$, the probabilities of matching along the steady state can be written as

$$
\alpha_{E}^{b}=\beta\left(\frac{l_{F}^{b}}{l_{E}^{b}}\right)^{1-a}=\beta\left(\frac{1-\sigma}{\sigma}\right)^{1-a} \text { and } \alpha_{F}^{b}=\beta\left(\frac{l_{E}^{b}}{l_{F}^{b}}\right)^{a}=\beta\left(\frac{\sigma}{1-\sigma}\right)^{a} .
$$

Plugging these values for $\alpha_{E}^{b}$ and $\alpha_{F}^{b}$ into (17), we can finally explicitly solve the system for $l_{E}^{b}, l_{F}^{b}, l_{Y}^{b}$ and obtain

$$
\begin{aligned}
& l_{E}^{b}=\frac{n \gamma \sigma}{n \gamma+(\phi n+\rho)^{2}+(\phi n+\rho)\left(1+2 \beta \sigma^{a}(1-\sigma)^{1-a}\right)}, \\
& l_{F}^{b}=\frac{n \gamma(1-\sigma)}{n \gamma+(\phi n+\rho)^{2}+(\phi n+\rho)\left(1+2 \beta \sigma^{a}(1-\sigma)^{1-a}\right)}, \\
& l_{Y}^{b}=\frac{(\phi n+\rho)^{2}+(\phi n+\rho)\left(1+2 \beta \sigma^{a}(1-\sigma)^{1-a}\right)}{n \gamma+(\phi n+\rho)^{2}+(\phi n+\rho)\left(1+2 \beta \sigma^{a}(1-\sigma)^{1-a}\right)} .
\end{aligned}
$$

Comparative Statics. Let us analyze the relationship between employment in the industry of ideas $\left(l_{E}^{b}, l_{F}^{b}\right)$ and the main parameters of the model. First, it is immediate to prove that $\partial l_{i}^{b} / \partial \rho<0(i=E, F)$, that is, and rather reasonably, the higher the discount rate, the lower the amount of resources devoted to innovation. It is also $\partial l_{i}^{b} / \partial \phi<0(i=E, F)$ : the lower the willingness to substitute consumption over time (the higher $\phi$ ), the lower the employment in the innovation sector. Both these effects are standard in the class of horizontal innovation growth models.

\footnotetext{
${ }^{11}$ In particular, we divide the first equation by $\left(\alpha_{E}+1+n \phi+\rho\right)$, and the second equation by $\left(\alpha_{F}+1+n \phi+\rho\right)$.

${ }^{12}$ Here again, the fact that $d \bar{\theta}^{b} / d l_{F}$ is strictly positive strengthens the strategic complementarity between entrepreneurs and capitalists that we have originally uncovered in system (12).
} 
It is also apparent that $\partial l_{i}^{b} / \partial \beta<0(i=E, F)$, meaning that a higher productivity of the innovation function shifts resources from the industry of ideas to the final good sector. This instead, is in contrast to this class of growth models, where the researchers' productivity does not affect employment in the R\&D sector (Jones, 1995b).

Moreover, it is possible to prove that an increase in the entrepreneurs' bargaining power raises the number of entrepreneurs and lowers the number of capitalists: $\partial l_{E}^{b} / \partial \sigma>0$ and $\partial l_{F}^{b} / \partial \sigma<0 .{ }^{13}$ On the other hand, it is $\partial l_{i}^{b} / \partial n>0(i=E, F)$, that is to say, and in line with this class of growth models, the effect of the growth rate on the industry of ideas is positive.

Finally, it can be shown that $\partial l_{i}^{b} / \partial a>0(i=E, F)$ if and only if $\sigma<1 / 2$, implying that the productivity of entrepreneurs exerts a positive effect on the overall employment in the industry of ideas if and only if their barganing power is higher than that of capitalists.

\section{The Role of the Policy Maker}

In this section, we analyze the opportunity for the policy maker's intervention in the financial market of innovation. In particular, we first carry out the welfare analysis; we then compare the resulting optimal innovative efforts with the decentralized allocations obtained in Section 4. Finally, we identify the policy measure that induces the optimal total amount of resources devoted to innovation.

\subsection{Welfare Analysis}

The social planner problem can be expressed as

$$
\max _{c(t), l_{F}, l_{E}} \int_{0}^{\infty} \exp (-\rho t) \frac{c(t)^{1-\phi}-1}{1-\phi} d t .
$$

subject to the following constraints

$$
\begin{aligned}
& y=k^{\gamma}\left(A l_{Y}\right)^{1-\gamma} \text { and } \dot{A}=\beta L\left(l_{E}\right)^{a} \cdot\left(l_{F}\right)^{1-a} \\
& \dot{k}=y-c-n k \text { and } 1=l_{E}+l_{F}+l_{Y}
\end{aligned}
$$

\footnotetext{
${ }^{13}$ Differently from the previous ones, this and the following two statements require a few algebraic steps. We omit them however, as they are straightforward applications of differential calculus.
} 
where all variables of interest are expressed in per capita terms, that is, $c=C / L$, $y=Y / L, k=K / L$ and, again, $l_{i}=L_{i} / L$ for $i=E, F, Y$. This problem of dynamic optimization is fully worked out in Appendix A. The optimal allocation of employment is characterized by the following number of, respectively, entrepreneurs, financiers, and final good workers: ${ }^{14}$

$$
\begin{gathered}
l_{E}^{W}=a\left[1-\frac{\rho+\phi n}{1-\gamma}\left(\frac{\rho+n+\phi n}{\gamma}\right)^{\frac{\gamma}{1-\gamma}}\right], \\
l_{F}^{W}=(1-a)\left[1-\frac{\rho+\phi n}{1-\gamma}\left(\frac{\rho+n+\phi n}{\gamma}\right)^{\frac{\gamma}{1-\gamma}}\right] . \\
l_{Y}^{W}=\frac{\rho+\phi n}{1-\gamma}\left(\frac{\rho+n+\phi n}{\gamma}\right)^{\frac{\gamma}{1-\gamma}},
\end{gathered}
$$

Dividing (20) by (21), we obtain the optimal ratio entrepreneurs/financiers as $l_{E}^{W} / l_{F}^{W}=a /(1-a)$. We are now ready to compare the optimal innovative efforts to those obtained under a decentralized market.

\subsection{Optimal vs. Decentralized Innovative Efforts}

Consider first the case without bargaining frictions, where entrepreneurs and financiers are paid according to their marginal productivities. If we impose the equality between the left-hand sides of the first two equations of (12), exploit (13) and simplify $(\rho+\phi n)$, we obtain

$$
\frac{l_{E}^{c}}{l_{F}^{c}}=\left[\frac{a}{1-a} \cdot \frac{1+\rho+\phi n+\beta\left(\frac{l_{E}^{c}}{l_{F}^{c}}\right)^{a}}{1+\rho+\phi n+\beta\left(\frac{l_{E}^{c}}{l_{F}^{c}}\right)^{a-1}}\right]^{\frac{1}{2}} .
$$

While this equation cannot be solved exactly for the equilibrium ratio entrepreneurs/financiers, it allows us to show easily that this ratio is different from the optimal ratio. In fact, an equilibrium ratio $l_{E}^{c} / l_{F}^{c}$ is any fixed point of the function defined by the right-hand side of (23). While this function is strictly increasing in $l_{E} / l_{F}$ and may admit more than one fixed point, it is immediate to verify that $a /(1-a)$ is not a fixed point of this function, and hence it is not a general solution to equation (23).

Under Nash bargaining, the equilibrium ratio entrepreneurs/financiers is instead given by $l_{E}^{b} / l_{F}^{b}=\sigma /(1-\sigma)$, which again is different from the optimal ratio. Moreover,

\footnotetext{
${ }^{14}$ Note that, as it happens in this class of models (Jones, 1995b), the optimal allocation of employment does not depend on $\beta$.
} 
it is immediate to verify from (18), (19), (20) and (21), that the total employment in the industry of ideas under the Nash bargaining solution may be higher or lower than the optimal number, $l_{E}^{b}+l_{F}^{b} \gtrless l_{E}^{W}+l_{F}^{W}$.

There are three sources of market imperfections in this model that explain the suboptimality of the equilibrium innovative efforts. The first, which is standard in the class of innovation-driven growth models, is associated with the presence of imperfect competition in the intermediate good sector, and it gives rise to what is usually called the consumer surplus effect. Given that the incentive to innovate (the monopoly profit) is strictly lower than the overall social benefits from the innovation (the consumer surplus), this external effect induces too little innovative effort.

The second source of market friction is instead related to the search process introduced via the production technology of new ideas (1). Each entry in the innovation industry alters the research productivity of both entrepreneurs and capitalists. On the one hand, the entry of an entrepreneur (capitalist) lowers the productivity of all other entrepreneurs (capitalists). This negative effect reminds us of the familiar stepping on toes effect, and is due to the assumption of decreasing marginal productivity of both entrepreneurs and capitalists. This generates too much innovative effort. On the other hand, to the extent that input factors are technological complements in (1), the entry of an entrepreneur raises the productivity of capitalists, and viceversa. In other words, the higher the number of capitalists, the higher the chance of a successful matching for an entrepreneur, and viceversa. This novel external effect, that we could call easy matching effect, is positive and induces too little effort in the industry of ideas. ${ }^{15}$

Finally, where a bargaining process is assumed to solve the profit sharing problem of the two innovative actors (Subsection 4.1), a third market friction characterizes the economy, which generates an equilibrium ratio entrepreneurs/financiers that reflects their respective bargaining power $(\sigma, 1-\sigma)$, rather than their productivity in the innovation process $(a, 1-a)$. In general, whether the economy devotes too few or too many total labor resources to innovation, and whether the distribution of these resources is tilted towards entrepreneurs or financiers, ultimately depends on the relative strength of all these external effects characterizing the economy.

\footnotetext{
${ }^{15}$ More formally, given that economic agents have zero measure in our economy, when making their occupational choice, they perceive their productivity as constant, that is: $\dot{A}=\bar{\beta} L_{i}, i=E, F$. This $\bar{\beta}$, capturing the creativity of the marginal agent, is however equal to $\beta L_{i}^{a-1} L_{-i}^{1-a}$. Hence, $\bar{\beta}$ is a decreasing function of $L_{i}$ (stepping on toes effect), and an increasing function of $L_{-i}$ (easy matching effect).
} 


\subsection{The Optimal Tax/Subsidy on Monopolistic Profits}

Given that we have found an explicit solution for both optimal and equilibrium innovative efforts under Nash Bargaining, it may be interesting to characterize explicitly the optimal innovation policy. The policy we consider in this section is one of tax/subsidy on the monopolistic profits. Denote a profit subsidy rate (or tax rate if negative) by $s \in R$. As a result, the new monopoly profits can be written as $\pi(1+s)$. Subsidies (taxes) are assumed to be withdrawn (transferred) from (to) the representative household, so that its intertemporal budget constraint remains unaffected.

Ideally, the objective of the policy intervention would be the one of inducing the optimal shares of entrepreneurs and capitalists, $l_{E}^{W}, l_{F}^{W}$. This policy, however, is unfeasible for the simple reason that a single instrument cannot reach two distinct goals at the same time. In what follows, we first characterize the policy that equalizes the total innovative efforts to the socially optimal ones, $l_{E}^{W}+l_{F}^{W}$. We then argue that, even though the resulting ratio entrepreneurs vs. capitalists is different from the optimal ratio $l_{E}^{W} / l_{F}^{W}$, it is still welfare maximizing to devote this total amount of labor resources to innovation.

Along the steady state, the chance of a successful matching for either entrepreneurs or capitalists, as a function of the profit subsidy/tax, is worth respectively

$$
\begin{aligned}
& v_{E}^{0}(s)=\frac{\bar{\theta} \alpha_{E} \pi(1+s)}{(n \phi+\rho)\left(1+\alpha_{E}\right)+(n \phi+\rho)^{2}}, \\
& v_{F}^{0}(s)=\frac{(1-\bar{\theta}) \alpha_{F} \pi(1+s)}{(n \phi+\rho)\left(1+\alpha_{F}\right)+(n \phi+\rho)^{2}} .
\end{aligned}
$$

Going through exactly the same steps followed in Subsection 4.1, we finally obtain the equilibrium number of entrepreneurs and capitalists, again as a function of the profit subsidy/tax, as

$$
\begin{aligned}
& l_{E}^{b}(s)=\frac{n \gamma \sigma(1+s)}{n \gamma(1+s)+(\phi n+\rho)^{2}+(\phi n+\rho)\left(1+2 \beta \sigma^{a}(1-\sigma)^{1-a}\right)}, \\
& l_{F}^{b}(s)=\frac{n \gamma(1-\sigma)(1+s)}{n \gamma(1+s)+(\phi n+\rho)^{2}+(\phi n+\rho)\left(1+2 \beta \sigma^{a}(1-\sigma)^{1-a}\right)} .
\end{aligned}
$$

To obtain the total equilibrium innovative efforts equal to the socially optimal ones, 
we must then solve equation $l_{E}^{b}(s)+l_{F}^{b}(s)=l_{E}^{W}+l_{F}^{W}$ by $s$. We find

$$
1+\hat{s}=\frac{\left[(\phi n+\rho)^{2}+(\phi n+\rho)\left(1+2 \beta \sigma^{a}(1-\sigma)^{1-a}\right)\right]\left[1-\frac{\rho+\phi n}{1-\gamma}\left(\frac{\rho+n+\phi n}{\gamma}\right)^{\frac{\gamma}{1-\gamma}}\right]}{n \gamma\left[\frac{\rho+\phi n}{1-\gamma}\left(\frac{\rho+n+\phi n}{\gamma}\right)^{\frac{\gamma}{1-\gamma}}\right]} \lessgtr 1 .
$$

Exploiting the equilibrium expressions for $l_{E}^{b}, l_{F}^{b}, l_{E}^{W}, l_{F}^{W}$ found in Subsections 4.1 and 5.1, (26) can be expressed as ${ }^{16}$

$$
1+\hat{s}=\frac{1-l_{Y}^{W}}{l_{Y}^{W}} \frac{l_{Y}^{b}}{1-l_{Y}^{b}} .
$$

Implementing policy $\hat{s}$, however, is not enough to obtain the first-best allocation of labor resources. As it appears from expressions (24) and (25), this policy measure does not alter the equilibrium ratio entrepreneurs/capitalists, $l_{E}^{b}(s) / l_{F}^{b}(s)=\sigma /(1-\sigma)$, which is different from the socially optimal ratio, $a /(1-a)$. Ideally, the policy-maker would be called to an additional policy intervention to establish an institutional and legal system bringing $\sigma$ as close as possible to $a$, that is, a system such that the bargaining power of entrepreneurs and capitalists reflects their respective productivies in the innovation process. While a thorough analysis of such policy is out of the scope of this paper, we can however prove that $\hat{s}$ is still the optimal subsidy/tax rate even when $\sigma \neq a .^{17}$ In other words, it is still worth it (as a second-best policy) to induce a total amount of resources devoted to innovation equal to the socially optimal amount $\left(l_{E}^{b}(s)+l_{F}^{b}(s)=l_{E}^{W}+l_{F}^{W}\right)$, even when these resources are sub-optimally distributed according to the respective bargaining power of entrepreneurs and capitalists and not to their productivities.

\section{Concluding Remarks}

This paper has built a scale-free endogenous growth model with horizontal innovation. An innovation is the outcome of a successful matching between an entrepreneur with a good idea and a capitalist recognizing the value of that idea. Incentives to become

\footnotetext{
${ }^{16}$ To obtain the following expression, we have added and subtracted $n \gamma\left(1-l_{Y}^{W}\right) / n \gamma l_{Y}^{W}$ from (26).

${ }^{17}$ This statement can be easily proven exploiting the properties of system (27) in the technical appendix. While we obtain $l_{E}^{W} / l_{F}^{W}=a /(1-a)$ from the second and third equation of the system, the value for $l_{Y}^{W}$ given in (22) (and hence for its complement, $l_{E}^{W}+l_{F}^{W}$ ) is instead obtained from the other three equations, and independently of the ratio $l_{E}^{W} / l_{F}^{W}$.
} 
either entrepreneurs or capitalists come from the possibility of sharing the monopoly profits associated with any innovation. The model investigates the occupational choice of economic agents across the three possible activities they may undertake in this economy: entrepreneurial, capitalistic and manufacturing activities. The occupational equilibrium is defined as that configuration for which the expected returns from the three activities are identical.

We have identified the stationary equilibrium conditions of this economy. We have then investigated the characteristics of the equilibria and compared them to the optimal allocation. A dual role for the policy maker emerges from the analysis. On the one hand, the presence of search (and bargaining) frictions in the financial market of innovation calls for the policy maker's intervention to correct them and help restore optimality. On the other hand, in a world with multiple equilibria, where coordination failures between entrepreneurs and financiers are possible, public policy can in principle help the economy converge towards a better equilibrium.

In fact, the economy described above is potentially subject to a most disruptive coordination failure in the financial market of innovation, in which the labor resources devoted to innovation are null. This "no-growth trap" (as any other coordination failure) can easily be given a self-fulfilling interpretation. Innovators are willing to spend their intellectual resources to discover a new idea only if they have the chance to meet a financier. At the same time, financiers are willing to spend their intellectual resources to evaluate the profitability of ideas only if they have the chance to meet valuable innovators. Hence, a coordination failure is possible, in which pessimistic expectations may dissuade everybody from acting as either an entrepreneur or as a capitalist. As a result, the innovation process stops abruptly and the economy stagnates forever.

The possibility of coordination failures across economic agents may contribute to explain why the venture capital industry may fail to take off even in potentially highly innovative economies. The lack of a favorable entrepreneurial climate may induce the innovative actors of the society to expect nobody involved in the innovation process. Unfortunately, these pessimistic expectations may turn out to be self-fulfilling. In this respect, the role of the policy maker might be crucial in providing a coordination device towards a more innovative balanced growth path, thus liberating the entrepreneurial spirits of the economy. 


\section{References}

[1] Aghion, P. and P. Howitt (1992). "A Model of Growth Through Creative Destruction". Econometrica, 60, 323-351.

[2] Aghion P., S. Bond, A. Klemm, I. Marinescu (2004). "Technology and Financial Structure: Are Innovative Firms different?". Journal of the European Economic Association, 2, 277-288.

[3] Almeida, H. and M. Campello (2004). "Financial Constraints, Asset Tangibility, and Corporate Investment". Review of Financial Studies, 20, 1429-1460.

[4] Arrow, K.J. (1962). "Economic welfare and the allocation of resources for invention", in Nelson, R. (Ed.), The Rate and Direction of Inventive Activity, Princeton University Press, Princeton, NJ, USA.

[5] Bauer, C. and J.V. Rodriguez Mora (2012). "Equilibrium Intermediation and Resource Allocation With a Frictional Credit Market". Mimeo, University of Munich.

[6] Bhattacharya, S. and J. Ritter (1983). "Innovation and Communication: Signalling with Partial Disclosure". Review of Economic Studies, Vol. 50 pp. 331-346.

[7] Boadway, R., O. Secrieru and M. Vigneault (2005). "A Search Model of Venture Capital, Entrepreneurship, and Unemployment" Working Paper 05-24, Bank of Canada.

[8] Chiu, J., C. Meh, and R. Wright (2013). "Innovation and Growth with Financial, and other, Frictions". CQER Working Paper 13-01.

[9] Cipollone, A. and P. Giordani (2013). "Animal Spirits in Entrepreneurial Innovation: Theory and Evidence". Mimeo, LUISS.

[10] Cozzi, G. and P.E. Giordani (2011). "Ambiguity Attitude, R\&D Investments and Economic Growth". Journal of Evolutionary Economics, Vol. 21(2), 303-319.

[11] Diamond, P.A. (1982). "Wage Determination and Efficiency in Search Equilibrium". Review of Economic Studies, 49, 217-229.

[12] Gompers, P.A. and J. Lerner (1999). "The Venture Capital Cycle". MIT Press, Cambridge, MA. 
[13] Gompers, P.A. and J. Lerner (2000). "Money Chasing Deals? The Impact of Fund Inflows on Private Equity Valuation". Journal of Financial Economics 55, 281-325.

[14] Greenwood, J. J.M. Sanchez, and C. Wang (2010). "Financing Development: The Role of Information Costs." American Economic Review, 100(4): 1875-9.

[15] Grossman, G.M. and E. Helpman (1991a). "Quality Ladders in the Theory of Growth", Review of Economic Studies 58, 43-61.

[16] Grossman, G.M. and E. Helpman (1991b). "Innovation and Growth in the Global Economy". The MIT Press, Cambridge, MA.

[17] Hall, B.H. and J. Lerner (2010). "The Financing of R\&D and Innovation". In B.H. Hall and N. Rosenberg (eds.), Handbook of The Economics of Innovation, Elsevier-North Holland.

[18] Hosios, A. (1990). "On the efficiency of matching and related models of search and unemployment". Review of Economic Studies 57, 279-298.

[19] Inderst, R. and H. Muller (2004). "The Effect of Capital Market Characteristics on the Value of Start-up Firms". Journal of Financial Economics, 72, pp. 319-56.

[20] Jones, C.I. (1995a). "Time Series Tests of Endogeneous Growth Models", Quarterly Journal of Economics 110, 495-525.

[21] Jones, C.I. (1995b). "R\&D Based Models of Economic Growth", Journal of Political Economy,103(4), 759-84.

[22] King, R.H. and R. Levine (1993). "Finance, Entrepreneurship and Growth". Journal of Monetary Economics, 32 (1993) 513-542.

[23] Kortum, S. and J. Lerner (2000). "Assessing the Contribution of Venture Capital to Innovation". Rand Journal of Economics, 31, pp. 674-692.

[24] Lerner, J. (2010). "Boulevard of Broken Dreams: Why Public Efforts to Boost Entrepreneurship and Venture Capital Have Failed and What to Do About It". Princeton University Press, Princeton, NJ.

[25] Levine, R. (2005). "Finance and growth: Theory and evidence". In P. Aghion and S. Durlauf (eds), Handbook of Economic Growth. 
[26] Michelacci, C. and J. Suarez (2004). "Business Creation and the Stock Market". Review of Economic Studies, 71, pp. 459-481.

[27] Mortensen, D. T. (1982). "Property Rights and Efficiency in Mating, Racing and Related Games". American Economic Review, 72, 968-980.

[28] Phelps, E. (2009). "Toward a Model of Innovation and Performance Along the Lines of Knight, Keynes, Hayek and M. Polanyi". In Z. Acs, D. Audretsch and R. Strom (Eds), Entrepreneurship, Growth and Public Policy, Cambridge University Press, Cambridge.

[29] Pissarides, C. (1984). "Search Intensity, Job Advertising, and Efficiency". Journal of Labor Economics, 2, 128-143.

[30] Romer, P.M. (1990). "Endogeneous Technological Change", Journal of Political Economy 98, S71-S102.

[31] Silveira, R. and R. Wright (2007). "The Venture Capital Cycle". Unpublished manuscript.

[32] Silveira, R. and R. Wright (2010). "Search and the Market for Ideas". Journal of Economic Theory, 145(4), 1550-1573. 


\section{A Welfare Analysis}

This problem of dynamic optimization defined at the beginning of Section 5 presents three control variables, $c(t), l_{F}, l_{E}$, and two state variables, $k$ and $A$. The Hamiltonian writes as

$H\left(c, l_{E}, l_{F}, k, A\right)=\frac{c(t)^{1-\phi}-1}{1-\phi}+\lambda_{k}\left(k^{\gamma}\left(A l_{Y}\right)^{1-\gamma}-c-n k\right)+\lambda_{A}\left(\beta L\left(l_{E}\right)^{a} \cdot\left(l_{F}\right)^{1-a}\right)$,

from which we obtain the following 5 conditions:

$$
\left\{\begin{array}{c}
H_{c}=c(t)^{-\phi}-\lambda_{k}=0 \\
H_{l_{E}}=\lambda_{A} a L \beta\left(\frac{l_{F}}{l_{E}}\right)^{1-a}-\lambda_{k}(1-\gamma) \frac{y}{l_{y}}=0 \\
H_{l_{F}}=\lambda_{A}(1-a) L \beta\left(\frac{l_{E}}{l_{F}}\right)^{a}-\lambda_{k}(1-\gamma) \frac{y}{l_{y}}=0 \\
H_{k}=\lambda_{k}\left(\gamma \frac{y}{k}-n\right)=\rho \lambda_{k}-\dot{\lambda}_{k} \\
H_{A}=\lambda_{A}(1-\gamma) \frac{y}{A}=\rho \lambda_{A}-\dot{\lambda}_{A}
\end{array}\right.
$$

Working on $H_{l_{E}}$ and $H_{l_{F}}$ we immediately obtain that the optimal ratio entrepreneurs/financiers must be $l_{E} / l_{F}=a /(1-a)$.

To find the absolute values of $l_{E}$ and $l_{F}$ we now proceed as follows. We know that in steady state it must be $\dot{c} / c=n$. Taking logs and derivative from the first equation in (27), we then obtain $\dot{\lambda}_{k} / \lambda_{k}=-\phi n$. On the other hand, dividiing $H_{k}$ by $\lambda_{k}$ and $H_{A}$ by $\lambda_{A}$ we obtain

$$
\frac{\dot{\lambda}_{k}}{\lambda_{k}}=\rho-\left(\gamma\left(\frac{A}{k}\right)^{1-\gamma}\left(l_{Y}\right)^{1-\gamma}-n\right) \text { and } \frac{\dot{\lambda}_{A}}{\lambda_{A}}=\rho-(1-\gamma)\left(\frac{A}{k}\right)^{-\gamma}\left(l_{Y}\right)^{1-\gamma}
$$

where we have also exploited the expression for the production function $y$ stated in one of the problem's constraints. Solving the first of the two equations in (28) by $A / k$ and plugging it into the second, we obtain

$$
\frac{\dot{\lambda}_{A}}{\lambda_{A}}=\rho-(1-\gamma)\left(l_{Y}\right)^{1-\gamma}\left[\frac{1}{\gamma\left(l_{Y}\right)^{1-\gamma}}\left(\rho+n-\frac{\dot{\lambda}_{k}}{\lambda_{k}}\right)\right]^{-\frac{\gamma}{1-\gamma}} .
$$

Knowing that in steady state it is $\dot{\lambda}_{k} / \lambda_{k}=\dot{\lambda}_{A} / \lambda_{A}=-\phi n$, we can finally solve the last equation for $l_{Y}$ in function of all parameters of the model and obtain (22) in the main text. Given that $1=l_{E}+l_{F}+l_{Y}$, and that $l_{E} / l_{F}=a /(1-a)$, it is easy to characterize the optimal number of entrepreneurs and financiers as given in, respectively, (20) and (21). 